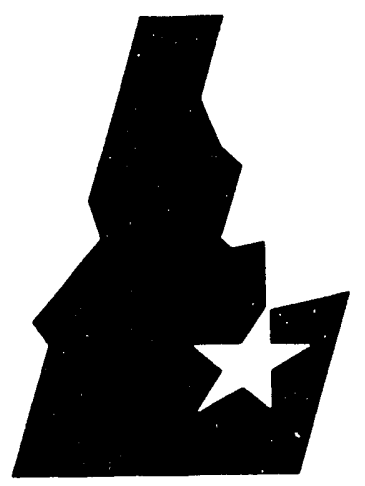

Idaho

National

Engineering

Laboratory

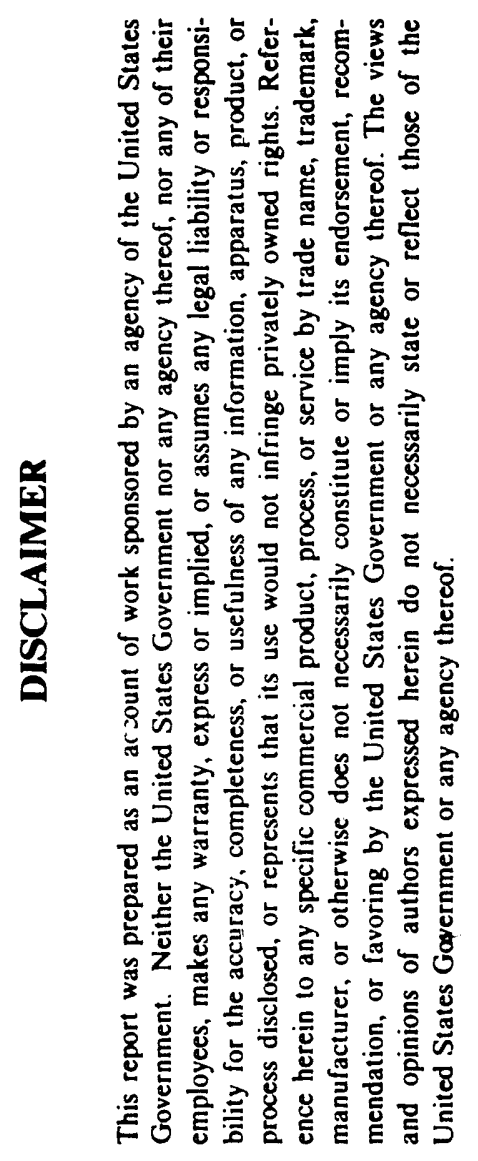

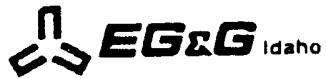

EGG-M-91262

DE92 003288

\title{
Trends in Fusion Reactor Safety Research
}

\author{
J. Stephen Herring, Douglas F. Holland \\ and Steven J. Piet
}

Fusion Safety Program

Idaho National Engineering Laboratory Idaho Falls, Idaho 83415-3523

Presented at the:

\author{
Second International Symposium on \\ Fusion Nuclear Technology \\ Karlsruhe, Germany
}

June 2-7, 1991

To be published in Fusion Engineering and Design

$$
\text { NOV } 221991
$$

This is a preprint of a paper intonded for publication in a journal or proceedings. Since changes may be made before publication, this preprint is made available with the understanding that it will not be cited or reproduced without permission of the author.

\section{MASTER}

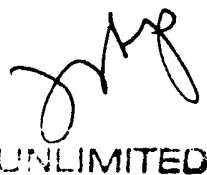




\title{
Trends in Fusion Reactor Safety Research ${ }^{a}$
}

\author{
J. Stephen Herring, Douglas F. Holland. and Steven J. Piet \\ Fusion Safety Program \\ Idaho National Engineering Laboratory \\ Idaho Falls, Idaho
}

\begin{abstract}
Fusion has the potential to be an attractive energy source. From the safety and environmental perspective, fusion must avoid concerns about catastrophic accidents and unsolvable waste disposal. In addition, fusion must achieve an acceptable level of risk from operational accidents that result in public exposure and economic loss. Finally, fusion reactors must control routine radioactive effluent, particularly tritium. Major progress in achieving this potential rests on development of low-activation materials or alternative fuels. The safety and performance of various material choices and furls for commercial fusion reactors can be investigated relatively inexpensively through reactor design studies. These studies bring together experts in a wide range of backgrounds and force the group to either agree on a reactor design or identify areas for further study.

Fusion reactors will be complex with distributed radioactive inventories. The next generation of experiments will be critical in demonstrating that acceptable levels of safe operation can be achieved. These machines will use materials which are available today and for which a large database exists (e.g. for 316 stainless steel). Researchers have developed a good understanding of the risks associated with operation of these devices. Specifically, consequences from coolant system failures, loss of vacuum events, tritium releases, and liquid metal reactions have been studied. Recent studies go beyond next step designs and investigate commercial reactor concerns including tritium release and liquid metal reactions.
\end{abstract}

\section{Introduction}

Several aspects must be considered to make fusion attractive from the safety and environmental perspective. First and fóremost, fusion must avoid being labeled as a possible threat of a catastrophic accident. The most credible approach in avoiding this concern is to reduce radioactive inventories and energy sources to the point that such accidents are not possible. There are two ways to achieve this potential: a.) through the

a This review was supported by the U.S. Department of Energy, Director of Energy Research, Office of Fusion Energy under DOE Contract No. DE-AC07-76IDO1570. 
use of low activation materials ${ }^{1,2}$ and b.) through advanced fuel cycles (i.e. $\mathrm{D}-{ }^{3} \mathrm{He}$ or $\mathrm{p}$ ${ }^{11} \mathrm{~B}$ ). Both of these approaches also reduce the concern about another aspect relating to safety and the environment, management of radioactive waste.

\section{Benefits of Low-Activation Materials and Alternate Fuels}

The ARIES study is a three-year effort led by Prof. Robert Conn of UCLA to explore potential designs for commercial tokamak reactors based on improved physics and materials. The ARIES-I and ARIES-III designs have provided valuable insights on these approaches. The use of $\mathrm{SiC}$ as a structure and helium as a coolant in the ARIES-I design resulted in low activation levels that reduced concerns about accidental releases and waste disposal with these materials. The use of tungsten for the divertor and lithium zirconate in the breeder material did result in activation concerns that were partially addressed by isotopic tailoring. For a low-activation design, all materials must be considered including structure, coolant, breeder, shield and divertor.

The nearly completed ARIES-III study, which is a tokamak reactor operating in the second stability regime and burning $\mathrm{D}-{ }^{3} \mathrm{He}$, identified several safety advantages and some disadvantages in the use of this advanced fuel. The reaction, $\mathrm{D}+{ }^{3} \mathrm{He} \rightarrow \mathrm{p}+{ }^{4} \mathrm{He}+$ $18.3 \mathrm{MeV}$, produces no neutrons directly, resulting in decreased activation. Neutrons and tritons are produced by parasitic D-D reactions, however. Since the plasma confinement requirements are more stringent when using ${ }^{3} \mathrm{He}$ as a fuel, the plasma current and temperature are higher in the ARIES-III design. Thus a single disruption may mobilize several kilograms of tungsten from the divertor surface and require the replacement of the divertor. Analyses are currently in progress to determine the impact of isotopic tailoring of the tungsten on the hazard posed by a disruption. A D- ${ }^{3} \mathrm{He}$ reactor also produces about 20 grams of tritium per day through D-D reactions. Although D-T reactions consume about half of that tritium before it leaves the plasma, the remaining 10 grams per day must either be burned, producing additional activation, or burned in a special-purpose D-T reactor or stored while the tritium decays.

A D- ${ }^{3} \mathrm{He}$ reactor requires a shield rather than a breeding blanket between the plasma and the magnets. Since D-D reactions produce neutrons and tritium in the D- ${ }^{3} \mathrm{He}$ plasma, the choice of a low activation material for that shield would significantly reduce the radioactive inventory still more. The $\mathrm{p}^{11} \mathrm{~B}$ reaction is truly aneutronic, but requires plasma conditions beyond near-term confinement capabilites.

\section{Recent Analysis of Activation Concerns}

Since low activation materials are not yet available, their advantages will not be apparent with next step designs such as the International Thermonuclear Experimental Reactor (ITER). As a result most researchers have focussed on concerns related to activation. Olsson, Devell, Johnsson and Gulden ${ }^{3}$ discuss the quantities and disposal methods for waste produced by ITER physics phase operation. They examine the criteria 
for disposal of wastes in German repositories KONRAD, and GORLEBEN and in the Swedish repositories SFR1, SFR3 and SFL3. They find that disposal of waste during and after the physics phase will require a storage capacity of between $1250 \mathrm{~m}^{3}$ and $6350 \mathrm{~m}^{3}$, depending on disposal site and on whether the blanket is replaced at the end of the physics phase.

Koch and Kazimi compare the radioactive waste generated by the Experimental Breeder Reactor - II (EBR-II) and ITER ${ }^{4}$. These two experiments are essentially the minimum size for showing the technological feasibility of a fast breeder fission reactor and of a fusion reactor, respectively. The authors compare seven aspects of the radioactive inventory for each of the reactors after 10,000 years after operation. They found waste from the two experiments are comparably difficult to handle and store. The use of standard materials in ITER, rather than low-activation materials, leads to a high activation, comparable to that of fast fission reactors. These findings are another indication that lowactivation materials need to be developed in parallel with D-T reactors.

Oishi, et.al ${ }^{5}$, have performed a two-fold task in their investigation of low activation concrete for fusion facilities. A $600 \mathrm{~mm}$ diameter by $600 \mathrm{~mm}$ long concrete assembly was irradiated with D-T neutrons for 10 hours in the Fusion Neutronics Source (FNS) facility. One day after the irradiation, detectors measured the gamma-ray flux at eight locations within the assembly. The experimenters also calculated the gamma dose rates using two cross-section libraries, one based on the Evaluated Nuclear Data File B-III (ENDF/B-III) and another based on ENDF/B-IV. There was significant disagreement between experiment and calculation at deeper detector positions when the library based on ENDF/B-III was used. Conversely, they found good agreement between experiment and calculation when the library based on ENDF/B-IV was used.

Using the verified calculational method, based on ENDF/B-IV, Oishi, et.al, compared the activations of eight candidate concrete which might be used for shielding. The reference concrete consisted of granite, sand and portland cement. Borated concrete $\left(1 \% \mathrm{~B}_{4} \mathrm{C}\right)$ resulted in a lower activation dose rates of 12 to 20 percent of the reference case at the end surface of the assembly. Limestone concrete, with low sodium, aluminum and magnesium contents, had activation dose rates of 5 to 10 percent of the reference case at all points though the bulk shield. They concluded that the limestone concrete, using white cement, has excellent properties as a low activation concrete for an igloo shield surrounding a fusion reactor.

\section{Recent developments in analysis of operational concerns}

Yet another aspect of safety attractiveness concerns operational accidents. Because of the complexity of fusion devices and the distributed nature of the radioactive inventories, there is a concern that accidents resulting in small releases or economic loss may be frequent. It is essential that this concern be well understood and that the next step devices demonstrate the ability to operate with an acceptable level of safety. 
The European Fusion Programme Evaluation Board has set as a goal that no accident in a fusion reactor should require evacuation of the public. Cook and Gimblett ${ }^{6}$, have investigated the most important uncertainties involved in meeting that "no evacuation" goal. Using probabilistic methods, the authors have determined the dominant contributors to the overall uncertainty of meeting the target. They conclude that, for internally initiated events, containment failure can be made physically impossible, provided containment bypasses and direct containment failure by magnetic missile can be designed out.

Handa et.al. ${ }^{7}$ have performed several analyses of neutron shielding and activation on the Large Helical Device (LHD). Based on the estimated neutron source strength from D-D reactions in the LHD, they designed the required concrete shield and shield door, considered the effects of streaming and skyshine, determined the activation of the air and water and calculated the dose rates due to the activation of the experiment itself.

\section{In-vessel/Coolant Accidents}

ITER is an experimental facility which will be subjected to a variety of transients during its lifetime. Several groups of authors in this section have analyzed transients in the cooling system to assure that the reactor is as robust as possible in the face of anticipated disturbances in the cooling of in-vessel and plasma facing components.

Klippel and Komen ${ }^{8}$ have used RELAP5/MOD3 to analyze three loss-of-cooling accidents (LOCAs) and two loss-of-flow accidents (LOFAs) in the NET/ITER divertor cooling system. The LOCA scenarios are a break in the main cooling circuit cold leg, a break of a feeder line from an inlet ring collector and a break of a surge line to the pressurizer. All of the LOCA transients assumed no plasma shutdown. The loss-of-flow scenarios are a LOFA without plasma shutdown and a LOFA with plasma shutdown after $10 \mathrm{~s}$. A nearly linear temperature increase occurred in all the divertor plates during those transients where there was no plasma shutdown. During the LOFA transient with plasma shutdown after $10 \mathrm{~s}$, the divertor plates reached a maximum temperature of about 2970 $\mathrm{K}$. These results re-emphasize the importance of a rapid plasma shutdown whenever cooling of the plasma-facing components is disrupted.

In contrast, Han and $\mathrm{Cook}^{9}$ have calculated the temperature evolution of the components of a standard and low-activation version of the EEF Reference Reactor with immediate plasma shutdown. For the reference reactor version using standard materials first wall and blanket component temperatures rise slowly, with the first wall still below $1100 \mathrm{~K}$ after 10 days. The version using low-activation materials has a still more benign behavior, with the first wall never exceeding $850 \mathrm{~K}$. The tungsten divertor of the standard version rises to $2300 \mathrm{~K}$ within five minutes after the loss-of-coolant accident, while the lowactivation divertor peaks at $1250 \mathrm{~K}$. Thus, with the possible exception of the standard divertor, the afterheat in a fusion reactor appears to be manageable and a passively safe reactor could be developed if prompt plasma shutdown could be assured. 
G. Cambi et.al. ${ }^{10}$ have evaluated the risk associated with various accident sequences occuring within the vessel of an ITER-type machine during its Physics Phase. The accident sequences included large LOCAs inside and outside the vacuum vessel, loss of tightness in the plasma vacuum pumping system and breaks in vacuum vessel penetrations. The team analyzed a total of sixteen sequences and determined the probability, dose and risk for each sequence. The largest risks were due to a large LOCA outside the vacuum vessel from the Aqueous Lithium Salt Blanket module.

Ebert and Raeder ${ }^{11}$, examine loss-of-coolant, loss-of-flow, and loss-of-vacuum accidents particularly as they relate to the NET/ITER vacuum vessel. A loss-of-coolant accident or a loss-of-vacuum accident may result in a plasma disruption, temperature transients or pressurization of the vacuum vessel, chemical reactions or the mobilization of radioactivity. A LOCA external to the vacuum vessel could result in loss of heat removal from in-vessel components, pressurization of external volumes or the mobilization and dispersion of radioactivity. The authors conclude that the vacuum vessel plays a major safety role in containing the radioartive inventory. Potentially hazardous chemical reactions of steam or oxygen with the plasma-facing carbon armor can be avoided by limiting the temperature of the plasma-facing components (PFC) and by providing an inert gas zone surrounding the vacuum vessel. The designers recommend limiting cooling-water temperatures to $150^{\circ} \mathrm{C}$ to limit overpressurization of the vacuum vessel and of the building in a LOCA. An active plasma shutdown system, triggering shutdown within about one second, could avoid in-vessel component melting after a cooling disturbance. By design, natural circulation can cool in-vessel components after a pump failure or loss of power.

The reference material for ITER is $316 \mathrm{~L}$ stainless steel. Andritsos and Zucchetti ${ }^{12}$ have compared its afterheat with that of three other materials, the martensitic steel MANET, the nickel-free manganese austenitic steel AMCR 0033 and the low-activation austenic steel IF-B. The reference design has a first wall temperature peak of about $900^{\circ} \mathrm{C}$ some 3.5 hours after a loss-of-cooling accident. The peak temperature for AMCR 0033 and IF-B were $2000^{\circ} \mathrm{C}$ and $1600^{\circ} \mathrm{C}$ respectively, also 3.5 hours after the LOCA. MANET performed better than other three alloys, with a maximum first wall temperature of $700^{\circ} \mathrm{C}$ about 15 minutes after the LOCA. For all of the alloys, the temperature increases linearly about two months after the LOCA if absolutely no corrective actions are taken.

\section{Blanket Transients}

As fusion experiments move into the development of technology, it is of paramount importance that the blankets operate safely in both routine and off-normal situations. Three papers in this section deal with experiments and analyses which will increase blanket safety. 
To further increase the operational safety of ITER, Ying, Raffray and Abdou ${ }^{13}$ consider the benefits of natural convection for a solid breeder blanket. Their analyses indicate that, after a complete loss-of-flow in an ITER-like blanket with poloidal coolant channels, two-phase natural circulation is sufficient to prevent dryout for a $15 \mathrm{~m}$ elevation head and a three-loop heat transport system. The design of the flow-channels and the thermal-hydraulic coupling must permit stable steady-state operation when vapor is present in the coolant channels.

One of the current blanket concepts uses lithium-lead as the breeder/neutron multiplier and water as the coolant. Savaterri and Gemelli ${ }^{14}$ describe the realistic simulation of metal-water interactions within the blanket due to a cooling tube rupture. The Blanket Safety Test (BLAST) facility, used in these experiments, has simulated eight such transients by injecting subcooled water into a stagnant pool of liquid $\mathrm{Pb}-17 \mathrm{Li}$. The simulations indicate that mixing is the governing factor in the metal-water interaction process. All of the BLAST experiments indicate that the chemical reaction is self-limiting and that reaction products insulate the melt from the water, making energetic vapor explosions unlikely. Small water injection rates, however, may lead to the formation of a water bubble within the melt, insulated by solid $\mathrm{LiOH}$ or $\mathrm{Li}_{2} \mathrm{O}$. Destruction of the bubble insulation could lead to more severe local conditions than occur in large break accidents.

In a related paper on the characteristics of $\mathrm{Pb}-17 \mathrm{Li}$, Casini, Rocco and Zucchetti ${ }^{15}$ discuss the problems of lead and impurity activation when lithium-lead is used in power reactors. In the short-term (i.e. accidental release) case, ${ }^{210} \mathrm{Po}$ and ${ }^{203} \mathrm{Hg}$ are the dominant isotopes in terms of environmental doses. If one assumes complete release of the polonium, acceptable off-site doses require impossible levels of breeder purification. On the other hand, experimental release data for polonium and mercury from $\mathrm{Pb}-17 \mathrm{Li}$ indicate that off-site doses will be acceptable. Hands-on recycling of the pure Pb-17Li breeder is possible 20 years after shutdown, though recycling of an alloy containing $1 \mathrm{ppm}$ silver would require remote handling.

\section{Routine release of tritium and tritium waste}

Finally, the routine loss of tritium is a safety and environmental concern. Of particular concern is the blanket since the high temperatures and high surface areas needed for heat transfer also facilitate tritium permeation.

Raepsaet, Prout and Violante ${ }^{16}$ 'consider tritium control for a DEMO blanket option using helium-cooled $\mathrm{LiAlO}_{2}$. Tritium contamination of the coolant can occur during normal operation due to permeation through the first wall, breeder tubes or beryllium cladding. Control of permeation through the breeder tubes can be achieved either through permeation barriers or through control of the purge gas chemistry, keeping the pressure of the permeating species below $1 \mathrm{~Pa}$. Control of permeation through the first wall can be achieved only through permeation barriers on the inside of first wall cooling channels. 
Both permeation barriers and coolant chemistry control need to be addressed experimentally in the near future.

Mannone ${ }^{17}$ describes the criteria and procedures for handling tritiated wastes at the ETHEL facility at the JRC-Ispra. The facility, which is expected to begin radioactive operation in 1992, will handle multigram quantities of tritium in safety-related experiments. The paper describes the classification of liquid and solid waste and the methods used in handling each type.

Dose calculations for routine releases show a wide variation. H.-W. Bartels ${ }^{18}$ compared 20 models for predicting the dose to the most exposed individual due at a daily release of $10 \mathrm{Ci}$ of $\mathrm{HTO}$. He found that the calculations varied by a factor of 500 , from 0.15 to $75 \mu \mathrm{Sv} / \mathrm{a}$. The main reasons for the variations were different assumptions on the atmospheric dispersion, climate, and ratio of ingestion and inhalation doses.

\section{Conclusions}

Two key issues adversely affecting the fission industry today are the possibility and fear of catastrophic accidents and the dilemma in disposing of radioactive waste. The use of low-activation materials and, perhaps, the use of alternate fuels can help fusion solve these twin problems. A few of the papers in this section have addressed those concerns, but more work needs to be done in defining and developing the role of LAM and alternate fuels.

Because low activation materials are not available for next step designs, most current research is focused on activation concerns. Several good papers in the section describe analyses supporting the safe operation of the next generation of experiments. The worldwide fusion community must demonsisate during the next decade that these inherently complex machines are robust in the face of a variety of transients and that they can be operated safely on a routine basis.

\section{References}

1. S. J. Piet, et.al., Accident Safety Comparisons of Elements to Define Low Activation Materials, EGG-FSP-8552, EG\&G Idaho, Inc. (July 1989).

2. Steven J. Piet, Edward T. Cheng, Steve Fetter and J. Stephen Herring, Initial Integration of Accident Safety, Waste Management, Recycling, Effluent and Maintenance Considerations for Low-Activation Materials, Fusion Technology, Vol. 19, 146-161, Jan. 1991.

3. G. Olsson, L. Devell, B. Johnsson and W. Gulden, Quantification and Disposal of Radioactive Waste trom ITER Operation, paper 100, this conference. 
4. M. Koch and M. S. Kazimi, A comparison of Radioactive Waste from an Experimental Fast Fission Reactor and an Experimental D-T Fusion Reactor, Paper 121, this conference.

5. Koji Oishi, Kiyoshi Minami, Yujiro Ikeda, Kazuaki Kosako and Tomoo Nakamura, Verification of Dose Rate Calculation and Selection Study on Low Activation Concrete in Fusion Facilities, paper 70, this conference.

6. I. Cook and C. G. Gimblett, A Risk Perspective on Fusion Safety Phenomena, paper 31, this conference.

7. Hiroyuki Handa, Katsumi Hayashi, Yuichi Ogawa, Yoichi Sakuma, Haruo Obayashi, Osamu Motojimi and Osamu Sato, Radiation Protection Concepts of Large Helical Device Facility, paper 39, this conference.

8. H. Th. Klippel and E. M. J. Komen, Analysis of Loss-of-Coolant and Loss-of-Flow Accidents in the divertor Cooling System of NET/ITER, paper 27, this conference.

9. W. E. Han and I. Cook, Temperature Transients in Reference Tokamak Reactors Following Loss of Coolant, paper 29, this conference.

10. G. Cambi, G. Cavallone, T. Palma and S. Sarto, Risk Evaluation of Critical InVessel Accident Sequences for a Next Step Tokamak Machine, Paper 61, this conference.

11. Edgar Ebert and Jürgen Raeder, LOCA, LOFA and LOVA Analyses Pertaining to NET/ITER Safety Design Guidance, paper 104, this conference.

12. F. Andritsos and M. Zucchetti, Afterheat in Fusion Structural Materials and Thermal Transient Scenarios in ITER, paper 139, this conference.

13. Alice Y. Ying, A. Rene Raffray and Mohamed A. Abdou, Benefits of Natural Convection in Solid Breeder Blankets with Poloidal Coolant Channels under LOFA Conditions, paper 305 , this conference.

14. C. Savaterri and A. Gemelli, Lithium-Lead/Water Interaction: Large Break Experiments, paper 318, this conference.

15. G. Casini, P. Rocco and M. Zucchetti, Radioactivity Effects of Pb-17Li in Fusion Power Reactors, paper 26, this conference.

16. X. Raepsaet, E. Prout and V. Violante, Some Consideration on Tritium Control for the European Ceramic B.I.T Demo Blanket, paper 50, this conference.

17. F. Mannone, Basis Criteria and Current Procedures for Routine Management of Tritiated Wastes at the JRC-Ispra, paper 38, this conference.

18. H.-W. Bartels, Comparison of Predicted Doses due to a Continuous HTO Release, paper 146, this conference. 

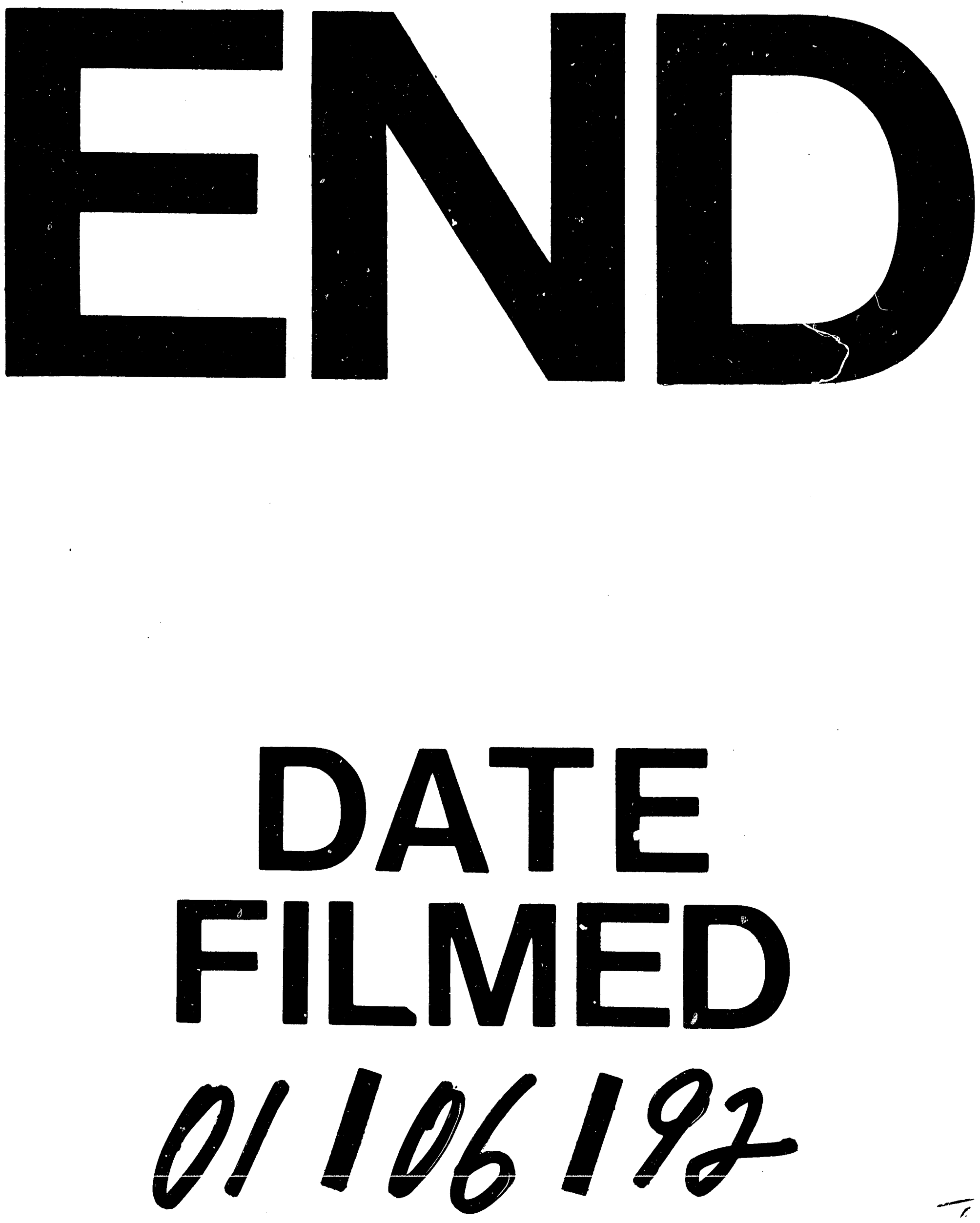
